\title{
Contratación de un Modelo de Formación Laboral
}

\author{
Sánchez Sánchez, Arturo \\ Universidad Autónoma de Tlaxcala, México \\ artuross1@hotmail.com \\ Molina Ruíz, Héctor Daniel \\ Universidad Autónoma del Estado de \\ Hidalgo, México \\ hmolina@uaeh.edu.mx
}

Resumen - Los estudios organizacionales muestran que el clima laboral es un factor preponderante en la explicación de las relaciones colaborativas entre empleados y directivos. En este sentido, la violencia laboral ha sido identificada como un factor adyacente a la formación laboral ya que ésta supone conflictos interpersonales y de tareas que inhiben la productividad y competitividad. En el marco del clima de relaciones y la violencia laboral, el presente estudio se inserta en la discusión acerca del sexismo como factor inhibitorio de las relaciones productivas. Se llevó a cabo una selección no probabilística de 258 estudiantes para establecer la confiabilidad y validez de un instrumento que pondera el grado de violencia formativa considerando ocho dimensiones de análisis. Los resultados muestran que el factor de benevolencia es el indicador reflejante de la violencia laboral $(\beta=0,69)$, aunque los parámetros de ajuste recomiendan la aceptación de la hipótesis alterna según la cual las

\author{
Carreón Guillén, Javier \\ Universidad Nacional Autónoma de México, \\ México \\ javierg@unam.mx \\ García Lirios, Cruz \\ Universidad Autónoma del Estado de México, \\ México \\ cgarcial213@profesor.uaemex.mx
}

relaciones especificadas son diferentes a los datos obtenidos [X2 = 15,25 (2gl) $p=0,000 ; \mathrm{GFI}=0,950$; $\mathrm{RMR}=0,009]$. En referencia a la relación entre sexismo benevolente y violencia laboral, los hallazgos del presente trabajo fueron discutidos.

Palabras Claves - Formación; organización violencia; sexismo; benevolencia.

Abstract - Organizational studies show that the working environment is an important factor in explaining collaborative relationships between employees and management. In this sense, workplace violence has been identified as an adjacent training because it involves interpersonal conflicts and tasks that inhibit productivity and competitiveness. Under the climate of relations and workplace violence, this study is inserted into the discussion about sexism as an inhibitory factor of productive relations. It conducted a nonrandom selection of 258 students to establish the reliability and validity of an instrument that weighs 
the degree of violence considering formative eight dimensions of analysis. The results show that the factor of benevolence is the reflective indicator of workplace violence $(\beta=$ 0.69 ), although the adjustment parameters recommend the acceptance of the alternative hypothesis that the specified relationships are different from the data [X2 = 15.25 (2df) $\mathrm{p}=0.000 ; \mathrm{GFI}=0.950 ; \mathrm{RMR}=$ $0.009]$. Referring to the relationship between benevolent sexism and workplace violence, the findings of this study were discussed.

Keywords - Training; organizational violence; sexism; benevolence.

\section{INTRODUCCIÓN}

El presente trabajo se inscribe en la disciplina de Trabajo Social, área de estudios de la formación laboral, incluye conceptos relativos a la psicología organizacional como es el caso del clima y el liderazgo, la sociología del trabajo como es el caso del institucionalismo y la economía del desarrollo como es el caso de la salud, la educación y el empleo.

En tal sentido es que el objetivo del presente estudio es establecer la confiabilidad y la validez de un instrumento que mide la formación laboral con la finalidad de contratar un modelo para el estudio del fenómeno en las Instituciones de Edu- cación Superior (IES) que atraviesan por un contexto de evaluación, acreditación y certificación de la calidad de sus procesos y productos, pero que en lugar de alcanzar tales objetivos y metas, más bien desarrollan climas de violencia que inhiben el efecto del institucionalismo educativo y reflejan una cultura laboral autocrática, centrada en una comunicación unilateral, una motivación unidireccional y un compromiso unipersonal.

Es así como el concepto de red formativa profesional, entendida como un conjunto de nodos centrales y periféricos en torno a los cuales se establecen relaciones simétricas o asimétricas de interacción. En el primer caso, los nodos centrales se distancian de los nodos periféricos. La brecha informacional entre los nodos es explicada por la transferencia discontinua de conocimiento. En el segundo caso, las diferencias entre los nodos centrales y periféricos se reducen a su mínima expresión facilitando el intercambio de información.

En el ámbito organizacional educativo, la formación laboral es el 
proceso en torno al cual se espera desarrollar las competencias que permitirán la inserción laboral del estudiante. En este sentido, los convenios de colaboración entre universidades y empresas están orientados a ajustar las habilidades y conocimientos de los estudiantes a los requerimientos del mercado local y global. Ello supone relaciones simétricas entre los participantes ya que la confianza, cooperación, compromiso, satisfacción y facilidad son indicadores de una formación laboral.

En contraste, cuando las relaciones asimétricas privan sobre los integrantes de una red, la desconfianza, egoísmo, insatisfacción y estrés aflora como un paradigma limitante de las relaciones de tareas y colaborativas.

\section{MARCO TEÓRICO}

Redes formativas académicas Las problemáticas educativas están imbricadas en el financiamiento de la formación laboral. En cuanto al presupuesto, la formación laboral global está liderada por Estados Unidos con cerca de 140 mil millones de dólares seguido de Japón,
Francia y Alemania. En último sitio, Argentina y México durante el periodo que de 1994 a 2007 (UNESCO, 2010).

Sin embargo, la inversión destinada a la investigación muestra diferencias poco significativas entre Australia, Corea, China, EU, Francia y Japón. Existen diferencias significativas entre el dinero proveniente de la industria y el financiamiento público u otros mecanismos de inversión en Alemania, Canadá, EU, Francia, Corea, Japón, México, Reino Unido y Suecia (UNESCO, 2010).

En el caso del financiamiento empresarial, se mantienen las diferencias entre los países, aunque se mantienen constantes en el periodo que va de 1998 a 2007 en Alemania, Argentina, Brasil, Canadá, Corea, China, EU, España, Francia y Japón. En el caso de México, se observa un financiamiento empresarial creciente que se duplicó en el periodo de análisis comprendido (UNESCO, 2010).

Ahora, bien la utilización del financiamiento disponible también se mantiene constante ya que de 1998 
a 2007 las instituciones y universidades de educación superior utilizaron un monto constante que sólo en los casos de Chile, Corea, España y Japón han decrecido, pero en los casos de Brasil, Canadá y EU se ha incrementado. En el caso de México, se observa un incremento sustancial a la mitad del periodo que termina con una disminución importante (UNESCO, 2010).

No obstante que el financiamiento se ha mantenido constante y la utilización de los recursos se ha incrementado y reducido en algunos casos, las diferencias entre el número de investigadores es sustancial entre los países analizados.

EU lidera el grupo con cerca de un millón 400 mil investigadores mientras que China registró en el 2007 el mismo número de investigadores, pero su aumento exponencial denota una baja calidad. Japón ocupa el tercer sitio seguido de Alemania con 600 mil y 200 mil respectivamente (UNESCO, 2010).

En el caso de América Latina; Brasil, México, Argentina y Chile ocupan los puestos noveno, décimo, undécimo y doceavo con cerca de 100 mil investigadores en los cuatro países. No obstante que hasta el año 2007 China y EU tenían el mismo número de investigadores, en cuanto a la producción de artículos existe una diferencia de 200 mil entre ambos países. Incluso, Alemania y Japón equiparan la producción de China (UNESCO, 2010).

Francia, Canadá e Italia ocupan puestos intermedios y Brasil es el país latino con mayor producción. Respecto a citas académicas, EU marca la pauta durante el periodo de 1997 a 2008 con respecto a los demás países mientras que México ocupa los últimos sitios. A pesar de que EU lidera cada uno de los rubros especificados, en cuanto a patentes es notablemente superado por Japón y los países latinos alcanzan las 50 mil patentes de 1998 a 2007 . El incremento de becas explica la emergencia de México en cuanto a patentes y su nula participación en los demás rubros. De 2000 a 2009 el monte se ha triplicado en México (UNESCO, 2010).

Las problemáticas educativas parecen explicarse desde el monto presupuestal y el financiamiento de 
la investigación en México con respecto a los países desarrollados. Las diferencias entre países no sólo son de orden financiero, sino además organizativo ya que Japón con 20 mil millones de dólares supera el número de patentes de EU que invierte 140 mil millones de dólares, aunque la producción de artículos y el número de citas justifica tal monto de inversión, pero en cuanto a innovaciones tecnológicas, Japón es un modelo de gestión para los países emergentes de América Latina.

En efecto, el desarrollo educativo, científico y tecnológico parece obedecer a una lógica organizacional en la que la Red Formativa Profesional y la Violencia Formativa Organizacional son factores que explicarían las diferencias entre países que asignan montos de inversión similares y las similitudes entre países que sustentan su producción desde diferentes montos presupuestales y financieros.

\section{Teoría de las redes formativas} Los marcos teóricos que explican el comportamiento de las redes de conocimiento a través de tecnologías de información y comunicación han establecido como factores determinantes a los principios valorativos, las creencias en torno a información y los principios normativos de la socialización de Internet y los dispositivos electrónicos. La relación entre estas variables con respecto al comportamiento tecnológico, ha sido establecida a partir del supuesto según el cual actitudes, percepciones e intenciones son mediadores del impacto de valores, creencias y normas sobre el uso de un dispositivo tecnológico (véase Figura 1).

La Teoría de las Redes de Conocimiento (NRT por sus siglas en inglés) plantea que las universidades y las empresas son nodos de intercambio de información que devienen en relaciones productivas a través de sus intercambios de conocimiento, desarrollo de proyectos interdisciplinares y flujos de adiestramientos (Adenike, 2011).

La innovación, desde la NRT, es un efecto del intercambio de información entre los proyectos de investigación y tecnología y la planificación estratégica del conocimiento. En tal sentido, una red de conocimiento implica la participa- 
Figura 1. Teoría de las redes formativas.

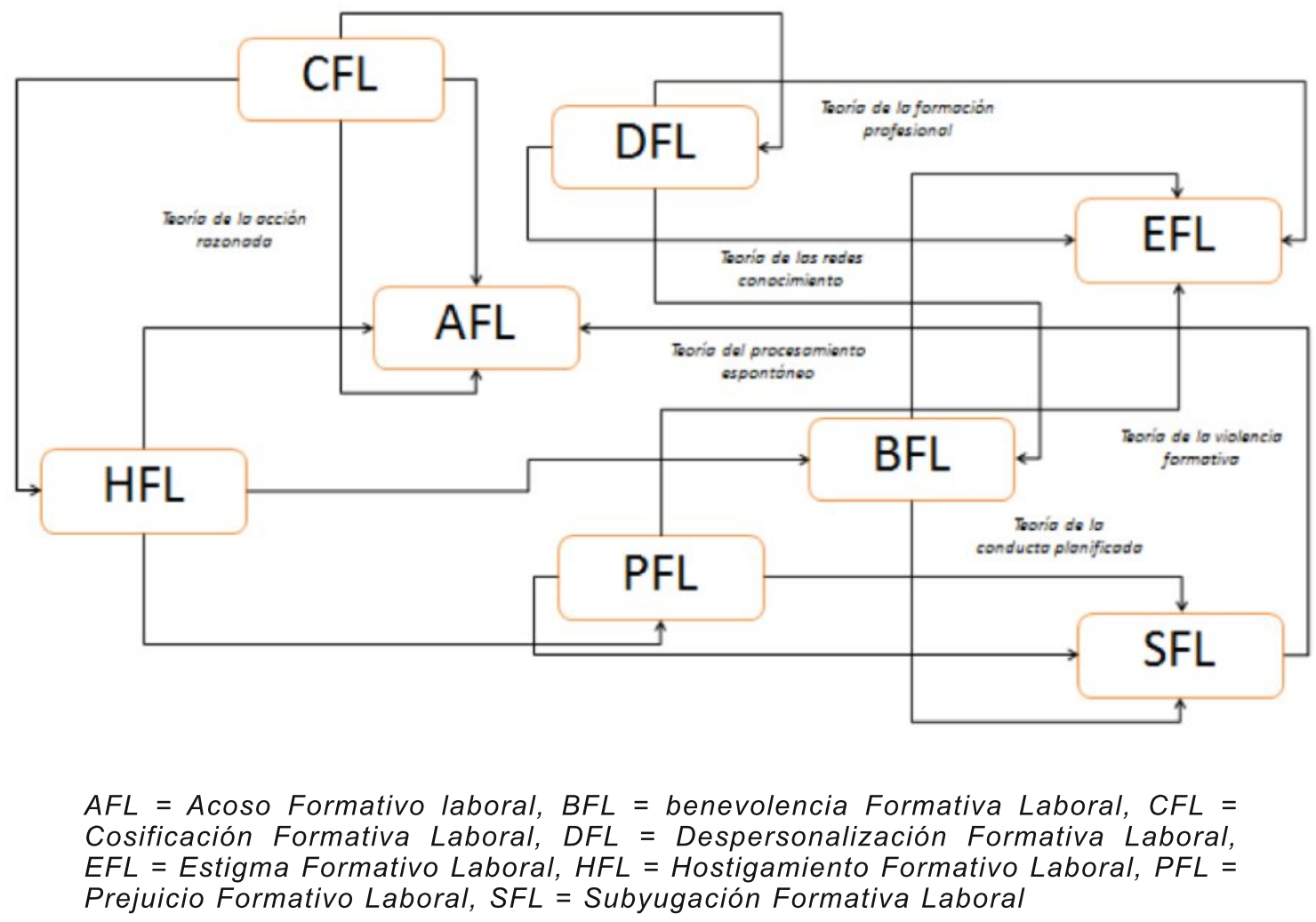

Fuente: Elaboración propia

ción colaborativa de especialistas y tecnólogos en torno a una actividad productiva-tecnológica. Por ello, la configuración de una red se lleva a cabo a partir de la estructura organizativa-colaborativa entre universidades y sectores industriales (Borjas, 2010).

Ambos conocimientos, codificado y tácito, simbolizan la construcción de una cultura organizacional-laboral-técnica en torno a la cual, la confianza resulta fundamental. La
NRT considera que de faltar el factor confianza, la configuración de una red no podría llevarse a cabo puesto que el aprendizaje colaborativo requiere de una distribución de responsabilidades en donde quien no sigue la dinámica laboral o clima organizacional, es excluida (Cuesta, 2012).

Son tres las teorías que emplean a las actitudes como una variable predictora de las intenciones $y$ comportamientos: Teoría de la Ac- 
ción Razonada, Teoría de la Conducta Planificada y Teoría del Procesamiento Espontáneo.

La Teoría de la Acción Razonada sostiene que las actitudes son mediadoras del efecto de las creencias sobre las intenciones y los comportamientos. Un incremento en las creencias aumenta las disposiciones hacia decisiones y acciones específicas y deliberadas. Se trata de un proceso que va de lo general, en cuanto a creencias, hacia lo particular en cuanto a intenciones $y$ acciones. No obstante, el poder predictivo de las creencias generales está acotado por la especificidad y unidimensionalidad de las actitudes. Dado que las actitudes transmiten el efecto de las creencias, delimitan sus indicadores en disposiciones probables de llevarse a cabo (Castel y Freundlich, 2010).

La Teoría de la Conducta Planificada advierte que el efecto de las creencias sobre el comportamiento esta mediado por actitudes y percepciones de control. Ante una situación o evento contingente, la percepción de control incrementa su poder predictivo de las intencio- nes y los comportamientos si y sólo si interactúa con disposiciones específicas. En la medida en que la percepción de control disminuye, su relación con las actitudes hace predecible un efecto mínimo en las decisiones. Necesariamente, el proceso deliberado y planificado de la toma de decisiones e implementación de estrategias requiere de una percepción de control consiste con las disposiciones hacia el objeto (Castro y Martins, 2010).

La Teoría del Procesamiento Espontáneo plantea a las actitudes como consecuencia de la activación de experiencias con el objeto actitudinal. Las actitudes son asociaciones entre evaluaciones de objetos. Una evaluación negativa incrementa la disposición y con ello la espontaneidad del comportamiento (Caykoylu, Egri, Havlovic y Bradley, 2011).

La Teoría de la Red Formativa Profesional explica las relaciones colaborativas orientadas al equilibrio entre demandas y recursos en contextos de escasez, incertidumbre, inseguridad y riesgo. La teoría anticipa la emergencia de factores 
tales como confianza, compromiso y satisfacción que a su vez determinan la innovación y eventualmente la felicidad organizacional.

Sin embargo, la teoría sólo explica una parte del proceso formativo profesional ya que en las organizaciones subyacen barreras que inhiben el desarrollo. En este sentido, ambivalencia y violencia organizacional son externas a la formación laboral.

Por consiguiente, la gestión del conocimiento supone redes formativas que innovan en situaciones adversas y contingentes, pero también subyacen a los conflictos y las asimetrías inherentes al clima organizacional.

La Teoría de la Violencia Formativa plantea que las diferencias entre sistemas productivos que invierten montos similares de dinero a sus procesos son resultado del clima organizacional; relaciones asimétricas, violentas y conflictivas. En este sentido, las organizaciones se aproximan al desequilibrio entre las demandas y los recursos, pero son la inequidad y la discrecionalidad las que permiten el ajuste de las relaciones de tareas a los objetivos difusos de las empresas.

La Teoría de la Violencia Formativa Organizacional advierte sobre la emergencia de un clima organizacional que se materializa en discursos de poder en los que las diferencias, conflictos y desencuentros son síntomas de una gestión discrecional, o bien, indican una gestión consensuada, pero relativa a la influencia de la mayoría sobre minorías.

La teoría anticipa el afloramiento de conflictos que a su explicarían el incremento de creatividad más que de confianza, las iniciativas y el esfuerzos personales más que la confianza y el compromiso grupal, así como el pragmatismo más que la satisfacción encaminados a la innovación, pero también hacia la conformidad.

Estudios de la formación laboral

Las Redes Formativas Profesionales (RFP) son sistemas de información y comunicación relativas al desarrollo de competencias educativas derivadas de sinergias institucionales y organizacionales. 
Las RFP implican sistemas tecnológicos informativos desde los que es posible construir una identidad académica o laboral siempre que los nodos formen consensos y corresponsabilidades en torno a la producción científica y tecnológica.

Al depender las RFP de las relaciones entre instituciones y organizaciones están expuestas a problemáticas inherentes a las relaciones colaborativas. De este modo, el clima laboral es el factor determinante de convenios, acuerdos y/o consensos orientados al desarrollo organizacional; industrial, científico y tecnológico, así como de las innovaciones de los grupos colaborativos.

No obstante que instituciones educativas y organizaciones con fines de lucro persigan objetivos comunes, la discrepancia entre la formación laboral responsable y la productividad desvinculada de la sustentabilidad es preponderante en los desencuentros y conflictos entre los actores académicos y empresariales.
Es por ello que las RFP son instrumentos de gestión de conocimientos e innovaciones que permitan superar la discrepancia entre el crecimiento industrial y el desarrollo sustentable.

Empero, el financiamiento empresarial que impulsa la especialización del conocimiento y la innovación tecnológica incentiva la producción científica hacia la optimización de los recursos naturales y con ello disemina una identidad laboral contraria a los valores de equidad, altruismo o biosférismo. Se trata de relaciones asimétricas en las que el verticalismo, el sexismo o el ostracismo son indicadores de un campo de poder organizacional desde el que se controla la gestión, la producción, la calidad y la innovación del conocimiento.

En términos de las redes organizacionales, convergen dos tipos de conocimiento: codificado y tácito.

El primero se refiere a las relaciones productivas en las que la comunicación de procedimientos, la captación y el adiestramiento se encargan de implementar la misión 
y la visión de la organización entre los recursos humanos (Cerrón, 2010).

El segundo tipo de conocimiento, se articula a partir del intercambio de procedimientos no escritos en un manual, pero transferidos por el personal más experimentado hacia el personal de nuevo ingreso. Se trata de creencias y valores en torno a la ejecución de tareas, la utilización del equipo técnico y los procedimientos de producción-distribución (Coronel, 2010).

El análisis de relaciones a partir de los discursos de profesores insertos en un convenio de colaboración entre una universidad pública y una organización con fines de lucro. El análisis de los significados en torno a la red de conocimiento por parte de los docentes evidencia un clima laboral de relaciones asimétricas. En torno a las cuales la ausencia del emprendimiento profesional es un factor a considerar par evaluar la eficacia del programa de prácticas profesionales.

En este sentido, las redes de conocimiento requieren de tres condiciones para subsistir: el poder horizontal, redistribuido entre los integrantes de la red y la carga de responsabilidad, orientada a todos y cada uno de los integrantes de la red. La solución a las problemáticas posteriores a la configuración de la red, está en la red misma. Por ello, las decisiones se establecen mediante un mecanismo de inducción más que de selección (Díaz, 2013).

Un factor esencial de la red son los traductores quienes poseen habilidades y conocimientos sobre las necesidades del personal operativo $y$ los requerimientos del personal administrativo en torno a la planificación estratégica de las metas (Gargallo, 2010).

Si se consideran lenguajes diferentes entre las necesidades de crecimiento de una empresa y la investigación básica, los traductores resultan fundamentales puesto que su formación laboral y su experiencia teórico-aplicada, son un eslabón entre empresarios, administradores y personal (Gil, 2010).

La autoeficacia es una percepción y/o una creencia motivada por ensayos de aciertos y errores per- 
sonales o impersonales llevados a cabo deliberada o discursivamente. Dado que la autoeficacia alude al fracaso, pero principalmente al éxito, aún a pesar de aquellos ensayos fallidos que incitan al logro, la percepción y creencia de autoeficacia se sustenta en la consecución de objetivos esperados más que en la competitividad, el reconocimiento o el aprendizaje vicario.

Si la autoeficacia es un sistema de percepciones y creencias enfocada al éxito, entonces el grupo al que pertenece o quiere pertenecer el agente autoeficaz está relacionado con el éxito. Debido a que los grupos son diversos, la autoeficacia varía en función de esta diversidad. Un grupo competitivo atribuye éxito a uno de sus integrantes cuando éste ha sobrepasado los logros antecedentes, que por cierto estaban fijados por el grupo. En este sentido, el concepto de autoeficiencia parece fehacientemente ajustado a la influencia de un grupo sobre los objetivos, el sistema y logros de un individuo (Anwar y Norulkamar, 2012).

Si la autoeficacia es un sistema de percepciones que incentivan los logros delimitando las capacidades eficaces, la autoeficiencia también sería un sistema de percepciones y creencias, pero a diferencia de la autoeficacia, éstas estarían orientadas a la ejecución de un procedimiento o tecnología. Los factores que impulsan la autoeficacia serían idénticos en el caso de la autoeficiencia. Si la competitividad, el reconocimiento y el aprendizaje vicario impulsan la autoeficacia, entonces la autoeficiencia también tendría ese impulso (Arnau y Montané, 2010).

Los estudios psicológicos actitudinales se han enfocado en su conceptualización, formación, activación, accesibilidad, estructura, función, predicción, cambio, inoculación, identidad y ambivalencia. Las actitudes han sido definidas a partir de dimensiones afectivas y racionales. Ambas dimensiones son el resultado de experiencias y expectativas. Esto implica su estructura: unidimensional o multidimensional que se configura en factores exógenos y endógenos. Es decir, cuando las actitudes activan decisiones y comportamientos causan un proceso periférico, emotivo, espontáneo, heurístico y ambi- 
valente. En contraste, cuando las actitudes transmiten los efectos de valores y creencias sobre las intenciones y acciones, son mediadoras endógenas de un proceso central, racional, deliberado, planificado y sistemático (Berdecia, González y Carrasquillo, 2012).

Los estudios psicológicos han demostrado diferencias significativas entre las actitudes hacia personas y actitudes hacia objetos. Las primeras se refieren a estereotipos o atributos y las segundas se refieren a evaluaciones o disposiciones. En ambas, la ambivalencia es un indicador de cambio cuando interaccionan creencias y evaluaciones formando disposiciones negativas y positivas hacia el objeto. Los conflictos se forman al interior de los componentes formados por creencias hacia el objeto. La resistencia a la persuasión, es una consecuencia de la ambivalencia actitudinal. Si el entorno amenaza la formación y la función de las actitudes, éstas adaptaran al individuo ante las contingencias. De este modo, las actitudes poseen dos funciones esenciales: egoístas y utilitaristas (Cardon, Gregoire, Stevens y Patel, 2013).
El cambio actitudinal alude a emociones y afectos consecuentes a los actos individuales y de los cuales las personas se sienten responsables. También se trata de la influencia social que ejercen los grupos docentes sobre los estudiantes. O bien, la recepción de mensajes persuasivos orientados al razonamiento central, o mensajes persuasivos dirigidos a la emotividad periférica. En general, el sistema actitudinal es sensible a la inestabilidad del objeto y a las variaciones cognitivas que inciden en la consistencia, estabilidad, predicción, competencia o moralidad del individuo (Celik, Turunc y Begenirbas, 2011).

El cambio consistente de actitudes está relacionado con su estructura multidimensional resultante de la presión mayoritaria. La diversidad de dimensiones implica una construcción consistente del cambio actitudinal. Es decir, las actitudes asumen una función de respuestas internalizadas ante situaciones constantes enmarcadas por los medios de comunicación masiva (Chiang, Méndez y Sánchez, 2010). 
El cambio actitudinal esta relacionado con el principio disuasivo de la inoculación. Antes del ataque de mensajes persuasivos, se induce la percepción de amenazas, riesgo e incertidumbre. En general, la sobreexposición a mensajes persuasivos induce una alta elaboración y con ello la persuasión. La emisión masiva de mensajes persuasivos, la motivación y las habilidades de manejo consecuentes pueden derivar en indefensión. Es decir, ante la ola de información las personas reducen su percepción de control y tienden a creer que los eventos son inconmensurables, impredecibles e incontrolables. O bien, los individuos se forman una identidad que consiste en identificarse con un grupo administrativo en referencia a un grupo docente. En el proceso de indefensión, el individuo construye el cambio de actitud y su reforzamiento de desesperanza. En el proceso identitario, es el grupo el que influye en el cambio actitudinal de la persona. La indefensión es un proceso de autovalidación o profecía auto cumplida En contraste, la identidad es una validación convergente de normas grupales (Chinchilla y Cruz, 2010).
La influencia social del grupo docente o grupo administrativo alude a las normas mayoritarias y a los principios minoritarios orientados al cambio actitudinal. La influencia de las mayorías propicia la conformidad individual y los principios minoritarios, el conflicto y el cambio actitudinal. Recientemente, el estilo de la minoría ha resultado ser el factor de influencia social y cambio actitudinal más permanente. Es decir, la construcción de consensos mayoritarios parece tener un efecto efímero y la construcción de disensos parece ofrecer un cambio constante (Díaz, Hernández y Roldán, 2012).

Los estudios de las actitudes hacia el comportamiento se han enfocado en su ambivalencia. Las personas tratan de equilibrar la información favorable y desfavorable hacia ese objeto disposicional manteniendo actitudes ambivalentes. Es decir, los objetos actitudinales son parte del entorno en el que se encuentran las personas y su necesidad de ordenarlo, predecirlo y controlarlo. Por ello, aunque el objeto actitudinal sea consistente con sus percepciones, valores y creencias, las personas deben contrastar 
dichos objetos con los comportamientos asociados a ellos (Figeiredo, Grau, Gil y García, 2012).

La educación es un sistema de redes de conocimiento que configuran un ciclo de enseñanza-aprendizaje. En el inicio del ciclo educativo, las redes de conocimiento son apenas un anteproyecto. Las estrategias de producción están orientadas por un paradigma emergente más que dominantes. Se trata de la verosimilitud de teorías porque el conocimiento apenas se sustenta por ideologías. La segunda etapa del ciclo educativo es la evaluación por pares la cual consiste en el ajuste de los proyectos a la política del grupo administrativo. Posteriormente, en la tercera etapa, se observa la difusión del conocimiento en los espacios académicos institucionales (Fuentes, Herrero y Gracia, 2010).

Los estudios sobre redes de conocimiento advierten que la formación de grupos y la planificación de proyectos son tan importantes como la confianza e identidad en torno a una organización, institución o universidad (Fuentes y Sánchez, 2010).
La formación de grupos tiene su origen en los procesos psicológicos sociales de la categorización, comparación, representación e identidad social en torno a los cuales el conflicto y el cambio, son los fundamentos de las redes de conocimiento (Galindo y Echavarría, 2011).

El conflicto, antecede al cambio. Se trata de relaciones asimétricas entre los integrantes de un grupo en referencia a integrantes de otro grupo considerado como ajeno a los intereses comunes de un grupo. El conflicto emerge cuando las diferencias entre los grupos son evidentes (González, Sánchez y López, 2011).

Sin embargo, el conflicto emerge en el momento en el que alguno de los estudiantes trasgrede el reglamento de prácticas afectando las transferencias de conocimiento. Puesto que los docentes-investigadores son los responsables de gestionar y capacitar a los estudiantes en su inserción a la misión y a la visión de las organizaciones, tienen que velar por el cumplimiento del reglamento y sancionar a quienes 
violen las reglas de colaboración (Holden y Karsh, 2010).

Otro tipo de conflicto, el relativo a la innovación definida como la influencia de una minoría perseverante en sus acciones con la intención de persuadir o disuadir a un grupo administrativo. Subyace al interior de la organización ó la universidad, se trata del conflicto en el que los estudiantes involucrados perciben un mayor aprovechamiento de sus capacidades y recursos. Consecuentemente, demandan mayor gestión y capacitación para lograr objetivos centrados en la innovación administrativa-tecnológica (López y López, 2011).

Por otra parte, el cambio es una consecuencia del conflicto. Se trata de un proceso en el que la conversión precede a la persuasión que activó un conflicto y una actitud central o periférica de necesidad de cognición (Molero, Recio y Cuadrado, 2010).

El cambio actitudinal en torno al cuestionamiento de convicciones, alude a un proceso disuasivo en el que la información puede ser racionalizada o emotiva. En el primer ca- so, la necesidad de cognición puede propiciar una disonancia en la que la información no concuerda con las expectativas. En el segundo caso, la información propicia emociones que incrementan las expectativas hacia el objeto informacional-actitudinal (Morales, Ariza, y Muñiz, 2012).

En este sentido, el cambio también es sinónimo de conversión en el que las actitudes hacia un objeto propician una modificación del comportamiento del individuo ante el grupo (Ríos, Téllez y Ferrer, 2010).

En el caso de las redes de conocimiento, el conflicto y el cambio son procesos esenciales para entender las barreras y las facilidades de transferencia del conocimiento entre grupos simétricos y asimétricos en torno a la información de un objeto, proceso, institución u organización (Rodríguez, Retamal, Lizana y Cornejo, 2011).

Los individuos establecen categorías, comparaciones, identidades y representaciones en torno a ellos mismos en relación con integrantes de un grupo y en referencia con otros individuos pertenecientes de 
otros grupos (Rojas, García y García, 2011).

Al establecer parámetros de comparación, los conflictos al interior de un grupo académico pueden trasladarsea los conflictos entre grupos organizacionales. Éste es el primer paso para la delimitación de la identidad o pertenencia a un grupo (Shrrof, Denenn y Ng, 2011).

La categorización intra e inter grupos, consiste en un conjunto de percepciones alrededor de los recursos, habilidades y capacidades al interior de un grupo en referencia a otro grupo. Si la percepción es el ordenamiento sesgado de los objetos, los grupos y sus individuos, sesgan sus apreciaciones al momento de evaluar sus actos y las de otros. Éste es el caso del sesgo de atribución en torno al cual, las percepciones individuales atribuyen a sus capacidades los logros y atribuyen a las capacidades de otros sus fracasos (Sobrados y Fernández, 2010).

Posterior a la categorización y comparación, subyace la identidad. Se trata de decisiones de pertenencia a partir de juicios atributivos sesgados. Si un estudiante percibe mayores posibilidades de crecimiento personal en algún grupo al que no pertenece, decidirá cambiarse o convertir sus ideas a las del grupo favorecido. En este sentido, la red de conocimiento sería aqueIla mayormente favorecida por los juicios y atribuciones individuales. En este punto del proceso de formación de grupo se construyen dos tipos de referencia: grupo docente y grupo administrativo (Teh, Chong, Yong, y Yew, 2010).

El grupo administrativo construye su identidad subyaciendo las capacidades del grupo docente. Es decir, la constitución de una red de conocimiento no sólo se efectúa a partir de las percepciones de capacidad de los integrantes de un grupo, sino también de las percepciones de incapacidad del grupo docente (Vargas y Arenas, 2012).

En la medida en que un grupo administrativo sesga sus juicios valorativos, traslada sus conflictos al grupo docente. El sesgo perceptivo se transforma en sesgo atributivo y termina como sesgo selectivo. Al enfocar el sesgo en el grupo do- 
cente, el individuo del grupo administrativo construye un entramado de representaciones en torno al cual se interpretan las capacidades, los recursos y los límites del grupo administrativo en referencia al grupo docente (Yáñez, Arenas y Ripoll, 2010).

La representación de las competencias grupales docente supone una evaluación de sus comportamientos por parte del individuo y su grupo docente. Se trata de un conjunto de emociones y cogniciones en torno a las causas del actuar del grupo docente en comparación a las acciones del grupo administrativo. Es decir, los individuos sólo quieren observar los actos que contradicen al grupo administrativo y tratan de minimizar sus efectos en las decisiones de las personas (Zampetakis y Moustakis, 2013).

En la medida en que el individuo tiene contacto con el grupo docente, incrementa sus emociones y cogniciones en torno al accionar del grupo docente. Precisamente, a partir de éstas experiencias es posible inferir procesos actitudinales que expliquen la exclusión del grupo docente por atribuírseles recur- sos y capacidades diferentes en comparación al grupo administrativo (Yuangion, 2011).

En dicho proceso de exclusión, subyace la consistencia emotivacognitiva-conductual que explica, las diferencias entre los grupos. Si el grupo administrativo excluye a los integrantes del grupo docente, entonces habrá mostrado una alta consistencia que amenaza la consistencia del grupo administrativo. Por ello, los individuos que pertenecen a un grupo administrativo, tienden a ver diferencias significativas con respecto al grupo docente y sus integrantes (Vargas, 2011).

No obstante, la consistencia del grupo administrativo está sesgada al compararse con el grupo docente puesto que una idea sesgada sólo puede ser un prejuicio más que un argumento (Prada, 2013).

En el ámbito de las redes de conocimiento, la consistencia del grupo administrativo y el grupo docente es incompatible. Para que una red de conocimiento funcione, se requiere de un grupo administrativo que pueda enlazar sus conocimientos con un grupo docente 
inconsistente en sus emociones, cogniciones y acciones, razones por las cuales, la transferencia de conocimiento del grupo administrativo vendría a justificar la sinergia de los grupos porque subsana la inconsistencia del grupo docente. Este proceso también puede observarse si el grupo administrativo es inconsistente y el grupo docente es consistente (Orantes, 2011).

Sin embargo, los individuos que perciben inconsistencia emotivacognitiva-conductual en torno a la producción de conocimiento en su grupo administrativo, terminan migrando al grupo docente puesto que éste les permitirá un mayor crecimiento personal. Este proceso de migración es de orden emotivo-cognitivo puesto que las emociones en torno al grupo docente, producen aversión al grupo administrativo, afinidad y adhesión al grupo docente (Omar, 2010).

Los traductores, aquellos que cuentan con conocimientos, capacidades y habilidades para gestionar sinergias entre el grupo administrativo y el grupo docente, tienden a buscar datos que corroboren sus gestiones de conocimiento. No obstante, la inaccesibilidad al grupo docente impide la gestión del conocimiento, la formación de sinergias y la transferencia de conocimientos. $\mathrm{Si}$ los individuos tienen acceso restringido a un grupo docente pueden mimetizarlo con el grupo administrativo y caer en el supuesto de compatibilidad natural del conocimiento tanto del grupo docente como del grupo administrativo. La consecuencia de ésta compatibilidad será la inhibición de la red de conocimiento y su devenir en corrupción, simulación o nepotismo en torno a la producción y transferencia del conocimiento. Es decir, un incremento en la inaccesibilidad al grupo docente, aumenta las probabilidades del fracaso de programas organizacionales, científicos y tecnológicos entre el grupo administrativo y el grupo docente (Medina, 2010).

Los traductores, en tanto gestores del conocimiento, son mediadores de las relaciones entre profesores y estudiantes. Cuando el clima organizacional entre el grupo administrativo y el grupo docente deviene en ambigüedad y adversidad más que transparencia y leal- 
tad, los implicados en las redes de conocimiento manipulan la información para perseguir sus intereses, los traductores deben persuadir a ambos grupos de la insostenibilidad de su relación. No es suficiente con diagnosticar las diferencias grupales, además es imprescindible reducir los riesgos y la incertidumbre potenciando los beneficios de cada enlace y nodo de la red de conocimiento (Manning, 2010).

Ahora bien, la consistencia afectivo-conductual entre ambos grupos implica creatividad la cual introduce en una dinámica innovadora a ambos grupos. Se trata de un clima organizacional flexible en el que se potencializan las ideas en torno a la producción y transferencia de conocimiento. Dado que las redes de conocimiento son diversas, en cada enlace o nodo es menester heterogeneizar la producción y transferencia del conocimiento. En la medida en que el clima organizacional sea blando, incrementa la confianza y la identidad al interior de ambos grupos (Long, 2013).

Confianza e identidad son el resultado de un tipo de información persuasiva conocida como creencia y el ámbito organizacional en el que se difunden las creencias es conocido como actitud hacia la red de conocimiento, sus integrantes y procesos. Un incremento de la información relativa a la red aumenta la certidumbre, producción y transferencia de conocimiento. En contraste, la disminución de información inhibe la relación grupal. Por consiguiente, las relaciones colaborativas e innovadoras repercuten en la productividad, empero, el estrés como agotamiento, despersonalización o frustración puede emerger como resultado del incremento de demandas productivas (Gil, 2010).

De este modo, la formación laboral está indicada por conflictos derivados de sus grados de discrecionalidad organizativa. A medida que ésta se intensifica, la inequidad se materializa en habitus monopólicos, pero una reducción a su mínima expresión genera consensos en la alta dirección (Guillén, Lleó y Perles, 2011).

En contraste, cuando la discrecionalidad es patrimonio discursivo de la alta dirección, la persuasión o la disuasión son producto de cam- 
pos monopólicos o consensuales. Es decir, la discrecionalidad como antecedente de habitus monopólico anticipa la violencia formativa ya que suprime la innovación y genera conformidad y obediencia, verticalismo, sexismo y ostracismo (Carreón, 2013).

\section{La Violencia Formativa Organiza-} cional sería el resultado de la interrelación entre mayorías y minorías relativas y simples que al momento de innovar aumentan o disminuyen su participación en la construcción de un clima organizacional (Tayo y Adeyemi, 2012).

Es así como las Redes Formativas Profesionales son grupos de poder que al centralizar sus decisiones generan una disidencia formativa y con ello la discusión para el consenso o bien, la utilización de la violencia como instrumento persuasivo o disuasivo de gestión del conocimiento y la innovación tecnológica (Carreón, 2011).

La Violencia Formativa Organizacional (VFO) a diferencia de la RFP está indicada por relaciones asimétricas e inequitativas entre los integrantes de la red de conocimiento.
De esta manera, la gestión es sustituida por dogmas; las libertades son desplazadas por la discrecionalidad; las oportunidades dan paso a las imposiciones, las capacidades son reducidas a su mínima expresión frente a los parentescos y las corresponsabilidades son inhibidas por atribuciones de culpabilidad.

Empero, investigaciones más recientes han demostrado que la socialización de información en las redes de conocimiento disemina su efecto sobre percepciones de utilidad y riesgo, así como sobre actitudes vinculadas con ansiedad $y$ adicción a las redes, principales determinantes del comportamiento.

De este modo, el comportamiento tecnológico es determinado por el procesamiento de información en torno a una red de conocimiento. Este efecto al ser mediado por decisiones de colaboración incrementa el poder predictivo de las creencias sobre las relaciones de tareas e interpersonales en una organización (Adenike, 2011).

Por su parte, las intenciones colaborativas suponen actitudes de confianza, capacidades percibidas y 
creencias informativas que al interrelacionarse determinan la toma de decisiones favorable o desfavorable a un grupo de conocimiento (Borjas, 2010).

Empero, el proceso de construcción del conocimiento no sería factible sin la formación de actitudes de confianza en las que los grupos colaborativos diseminan información que será categorizada en herramientas de aprendizaje o motivación orientada al logro de objetivos y metas (Cerrón, 2010).

En paralelo, las capacidades percibidas complementan la formación de categorías de información ya que se trata de habilidad y conocimientos en torno a la construcción de una red formativa profesional (Coronel, 2010).

No obstante, algunos estudios plantean que la formación laboral y la construcción de una red son procesos diferentes ya que suponen valores egoístas que contradicen los valores altruistas (Díaz, 2013). Se trata de un serie de normas grupales en torno a las cuales los individuos son formados profesionalmente, o bien, son orien- tados emocionalmente al forjarse una identidad (Cuesta, 2012). Empero, es la socialización de la información la que determinará el comportamiento de un individuo en un grupo colaborativo (Gargallo, 2010).

El estado del conocimiento ha explicado el rendimiento organizacional de grupos y redes colaborativas ante situaciones de escasez, incertidumbre, inseguridad y riesgo. Los individuos y grupos desarrollan climas de confianza potencializan su compromiso laboral y se aproximan a la satisfacción de vida, pero también implementan una gestión creativa y procesos innovadores como respuesta a la contingencia.

Sin embargo, el modelo esgrimido por el estado del conocimiento al suponer que la socialización del conocimiento consiste en creencias generales de información, supone efectos generales en cada uno de los factores mediadores de su relación con el comportamiento. Por consiguiente, la especificación de las dimensiones del comportamiento podría indicar que existen otros factores intermedios con respecto a la socialización. 
Se trata de ocho indicadores del comportamiento tecnológico los cuales explican la formación de un grupo colaborativo a partir del procesamiento de información.

En el caso de la confianza, el comportamiento tecnológico está indicado por relaciones colaborativas en las que los beneficios no serían en función de costos, sino más bien derivados de una interdependencia al momento de llevar a cabo una tarea determinada (Gil, 2010). Es decir, la formación laboral que supone el uso intensivo de tecnologías deviene de relaciones simétricas que un grupo establece para distribuir las habilidades y diseminar los conocimientos. Se trata de relaciones comprometidas ya que si un integrante no desarrolla las competencias laborales, entonces será excluido de un grupo que ha establecido una cultura de alta calidad productiva (Long, 2010). En este sentido, la colaboración es el resultad de objetivos compartidos, mientras que el individualismo sería un efecto del sistema de metas que premia el esfuerzo personal (Manning, 2010).
En el caso de la cooperación, a diferencia de la simple colaboración normativa, el comportamiento tecnológico supone habilidades y conocimientos especializados para el cumplimiento de propósitos. Es por ello que los grupos se ven orillados a establecer relaciones cooperativas ya que el grupo mismo debe intercambiar información, procesar estrategias o implementar técnicas que suponen el apoyo continuo entre sus integrantes (Medina, 2010).

Sin embargo, otro indicador del comportamiento tecnológico es la empatía entre sus integrantes ya que el trabajo intensivo y la consecución de objetivos o el cumplimiento de metas implica relaciones afectivas y emocionales para reducir lo conflictos personales a la ausencia de comunicación (Omar, 2010).

Respecto a la solidaridad, a diferencia de la colaboración o la cooperación, supone la formación laboral con base en la dinámica de equipos colaborativos al interior de la red de conocimiento. Mientras que la colaboración y la cooperación están determinadas por valo- 
res sociales, la solidaridad va más allá de los principios normativos o valorativos que unen a los grupos, se trata de una conciencia de escasez e incertidumbre que permite anticipar situaciones de desabasto compartiendo los recursos (Orantes, 2011).

En consecuencia, la propensión al futuro es el resultado de conductas solidarias que anticipan escenarios de riesgo. En efecto, los grupos colaborativos son motivados por estrategias de prevención y afrontamiento ante situaciones desfavorables a los grupos con los que comparten objetivos y metas (Prada, 2013).

Por último, el indicador por excelencia del comportamiento tecnológico es el emprendimiento o espíritu disidente. En efecto, el uso de una tecnología y más aún la formación de redes colaborativas no tendrían sentido si sólo se persiguieran ganancias a corto o mediano plazo. La formación laboral consiste en anticipar escenarios de escasez, riesgo e incertidumbre para el cual los grupos de conocimiento forman redes que en esencia son emprendedoras, disi- dentes de las situaciones que se avecinan o las catástrofes que se esperan (Vargas, 2011).

La especificación de relaciones plantea que la violencia formativa organizacional está indicada por ocho factores relativos al prejuicio, despersonalización, benevolencia, hostigamiento, subyugación, cosificación, estigma y acoso que conforman un clima de relaciones y de tareas en los que afloran discursos que reducen los méritos de los individuos $\mathrm{y}$ enaltecen las diferencias entre los grupos.

\section{MODELO DE FORMACIÓN LA-} BORAL

\section{Formulación}

¿Cuáles son los ejes y las trayectorias de las dimensiones de la formación laboral explicadas en los marcos teóricos, conceptuales y empíricos que anticiparían escenarios de violencia laboral en un contexto de IES con redes formativas y procesos institucionales, estructurados, racionales, deliberados, planificados sistemáticos desfavorables a la formación de talentos, pero favorables a la formación de agresores? 


\section{Hipótesis nula}

Las teorías de las redes de conocimiento, acción razonada, conducta planificada, procesamiento espontáneo, formación laboral y violencia formativa al explicar que: 1) el fenómeno de las diferencias entre líderes y empleados deriva de las asimetrías entre las demandas del entorno con respecto a los recursos y las capacidades internas de la organización; 2) propicia la emergencia de víctimas y victimarios circunscritos a climas de relaciones de violencia, ciclos de agresión y círculos de exclusión que; 3 ) favorece a quienes asumen un rol autoritario, una comunicación unilateral, una motivación unidireccional y un compromiso unipersonal con respecto a quienes son víctimas por asumir un rol colaborativo, una comunicación bilateral, una motivación bidireccional y un com-

Figura 2. Hipótesis de estudio.

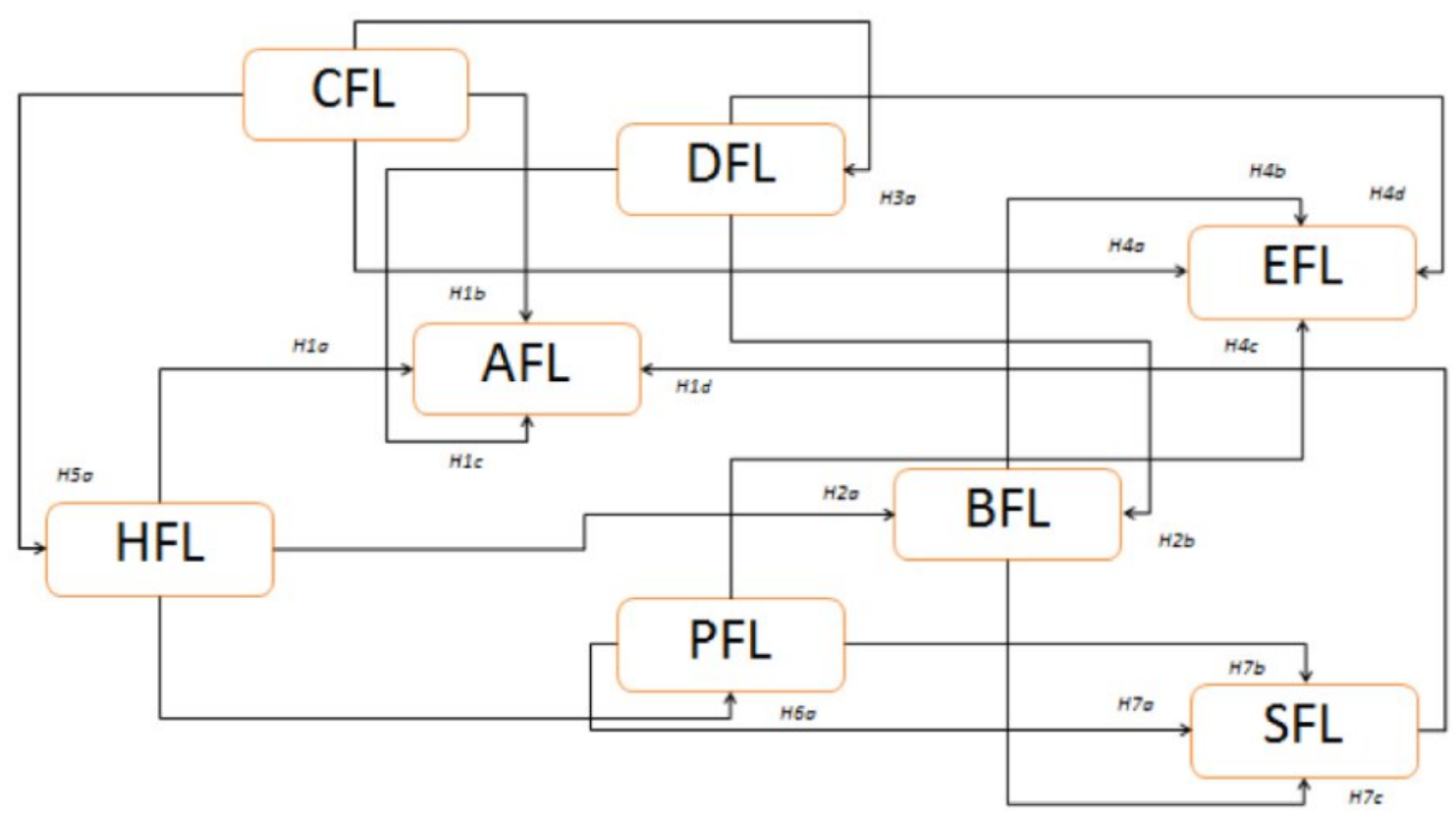

$\mathrm{AFL}=$ Acoso Formativo laboral, BFL = benevolencia Formativa Laboral, CFL = Cosificación Formativa Laboral, DFL = Despersonalización Formativa Laboral, $\mathrm{EFL}=$ Estigma Formativo Laboral, $\mathrm{HFL}=$ Hostigamiento Formativo Laboral, PFL = Prejuicio Formativo Laboral, SFL = Subyugación Formativa Laboral

Fuente: Elaboración propia 
promiso colectivo. Por consiguiente, los marcos teóricos, conceptuales y empíricos al predecir escenarios de violencia formativa laboral explicarán y anticiparán un contexto de violencia al interior de la IES de estudio que se ajustará a las observaciones empíricas en la institución académica (véase Figura 2).

\section{Hipótesis alterna}

No obstante que el estado del conocimiento ha explicado, anticipado y predecido un escenario de asimetrías y confrontaciones entre perfiles $y$ roles de víctimas $y$ victimarios, las interrelaciones entre los actores; administrativos, docentes y estudiantes más bien obedecen a una construcción particular de sus diferencias y similitudes. Por consiguiente, las teorías enunciadas no alcanzarán a explicar las particularidades del fenómeno de la formación laboral ni en su dimensión negativa como es el caso de la violencia ni en su dimensión positiva como es el caso de la cooperación ya que, más bien se gestarán relaciones complejas que ubican en ambos polos a los actores en comento.
MÉTODO

\section{Diseño}

Se llevó a cabo un estudio exploratorio, transversal de corte cualitativo y cuantitativo.

\section{Muestra}

Se realizó una selección no probabilística de 258 estudiantes de una universidad pública. El criterio de selección fue pertenecer al sistema de prácticas y servicio social en organizacionales e instituciones con y sin fines de lucro del municipio de Chimalhuacán, Estado de México.

\section{Instrumento}

Se utilizó la Escala de Violencia Formativa Organizacional de Carreón (2014) la cual incluye 32 aseveraciones en torno a prejuicio, despersonalización, benevolencia, hostigamiento, subyugación, cosificación, estigma y acoso con cinco opciones de respuesta que van desde "no se parece a mi situación" hasta "se parece mucho a mi situación" (véase tabla 1).

\section{Procedimiento}

Se entrevistaron y encuestaron a los participantes en las instalaciones de la universidad. Se les in- 


\section{Tabla 1. Operacionalización de variables.}

\begin{tabular}{c|c|} 
Factor & \multicolumn{1}{c|}{ Definición } \\
Acoso & $\begin{array}{l}\text { Grado de persecución a } \\
\text { individuos o grupos a los que } \\
\text { se les culpabiliza por los } \\
\text { resultados de la organización. }\end{array}$
\end{tabular}

\section{Benevolencia}

Despersonalización

Grado de confinamiento de individuos o grupos percibidos como vulnerables, marginados o excluidos en el entorno laboral.

\section{Cosificación}

\section{Reactivos}

29 a 32

\section{Estigma}

Hostigamiento

Prejuicio

Subyugación
Grado de indiferencia hacia individuos o grupos que participan en un mismo proceso colaborativo.

Grado de minimización de los logros de individuos o grupos que colaboran en un mismo proceso laboral.

\section{1 a 24}

9 a12
5 a 8
Grado de atribución de causalidad a individuos o grupos a los que se les asocia elementos negativos o desfavorables a la organización.

Grado de discursos y acciones dirigidas a individuos o grupos que participan en un mismo nivel colaborativo.

\section{Opciones}

$0=$ no se parece a mi situación, 1 = se parece muy poco a mi situación, 2 = se parece poco a mi situación, 3 = se parece en algo a mi situación, $4=$ se parece muchísimo a mi situación

$0=$ no se parece $a \mathrm{mi}$ situación, 1 = se parece muy poco a mi situación, 2 = se parece poco a mi situación, 3 = se parece en algo a mi situación, $4=$ se parece muchísimo a mi situación

$0=$ no se parece $a \mathrm{mi}$ situación, 1 = se parece muy poco a mi situación, 2 = se parece poco a mi situación, 3 = se parece en algo a mi situación, 4 = se parece muchísimo a mi situación

$0=$ no se parece a mi situación, 1 = se parece muy poco a mi situación, 2 = se parece poco a mi situación, 3 = se parece en algo a mi situación, 4 = se parece muchísimo a mi situación

35 a $28 \quad 0=$ no se parece a $\mathrm{mi}$ situación, 1 = se parece muy poco a mi situación, 2 = se parece poco a mi situación, 3 = se parece en algo a mi situación, 4 = se parece muchísimo a mi situación

13 a $160=$ no se parece a $\mathrm{mi}$ situación, 1 = se parece muy poco a mi situación, 2 = se parece poco a mi situación, 3 = se parece en algo a mi situación, 4 = se parece muchísimo a mi situación

1 a 4 $0=$ no se parece $a \mathrm{mi}$ situación, 1 = se parece muy poco a mi situación, 2 = se parece poco a mi situación, 3 = se parece en algo a mi situación, 4 = se parece muchísimo a mi situación

17 a $20 \quad 0=$ no se parece a $\mathrm{mi}$ situación, 1 = se parece muy poco a mi situación, 2 = se parece poco a mi situación, 3 = se parece en algo a mi situación, 4 = se parece muchísimo a mi situación

\section{Fuente: Elaboración propia}


formó que los resultados de la investigación no afectarían ni positiva ni negativamente su situación escolar. Se les pidió que contestaran honestamente a las preguntas y aseveraciones. Se les invitó a que consultaran los resultados en el informe final del grupo de investigación. Los datos fueron procesados en el Paquete Estadístico para Ciencias Sociales (SPSS por sus siglas en inglés) y el Software de Análisis de Momentos Estructurales (AMOS por sus siglas en inglés) en sus versiones 10 y 6.0

Análisis. Se utilizaron los parámetros de curtosis, alfa de Cronbach, coeficientes KMO, prueba de Bartlett, pesos factoriales, correlaciones de Pearson, covarianzas "phi", pesos "beta" y "gama", así como índices de ajuste y residuales a fin de contrastar el modelo de relaciones especificadas con los datos observados.

Normalidad. El valor curtosis cercano a la unidad fue asumido como evidencia de distribución normal de las respuestas de encuestados con respecto a las aseveraciones que miden las variables del estudio en un instrumento con opciones de respuesta y niveles de medición intervalar.

Validez. Los coeficientes KMO superiores a 0,600 y la prueba de Bartlett con nivele de significancia menor a 0,050 fueron asumidas como evidencia de correlaciones producto momento que facilitaron el análisis factorial exploratorio de componentes principales con rotación varimax. Posteriormente, los pesos factoriales superiores a 0,300 fueron considerados como evidencias de la maximización de varianza en cuanto a los factores derivados del análisis exploratorio. Los porcentajes de varianza explicada superiores a 0,20 fueron asumidos como evidencia de aceptación de la hipótesis nula.

Confiabilidad. El valor alfa de Cronbach superior a 0,70 fue asumido como suficiente para demostrar la consistencia interna de los indicadores con respecto a la escala general y las subescalas particulares. La correlación producto momento superior a 0,90 fue considerada como una evidencia de colinealidad y multicolinealidad las 
cuales significan que los ítems son similares en cuanto a sus contenidos.

Correlación. Los valores $r$ de Pearson cercanos a la unidad y al cero fueron descartados de posteriores análisis ya que significan relaciones colineales o espurias. En cambio, aquellos valores superiores a 0,30 e inferiores a 0,90 fueron asumidos como evidencias de relaciones de dependencia.

Covarianza. Los valores "phi" entre 0,30 y 0,90 fueron identificados como evidencias de relaciones de dependencia para el caso de variables categóricas o en combinación con variables continuas.

Estructura. Los valores "beta" entre variables exógenas y endógenas entre 0,30 y 0,90 fueron asumidas como evidencia de relaciones de dependencia. Del mismo modo, los valores "gamma" entre variables endógenas cercanos a cero o a la unidad fueron descartados de posteriores análisis.

Ajuste. El Índice de Bondad de Ajuste (GFI por sus siglas en inglés) cercano a la unidad fue asu- mido como evidencia de ajuste y aceptación de la hipótesis nula. Por el contrario, los valores inferiores a 0,975 fueron considerados como evidencia de rechazo de la hipótesis nula y aceptación de la hipótesis alterna.

Residual. Los valores cercanos a cero fueron asumidos como evidencia de ajuste entre las relaciones especificadas y los datos obtenidos, por consiguiente, se aceptó la hipótesis nula de ajuste entre ambos modelos. En contraste, los valores superiores a 0,007 fueron considerados como evidencia de rechazo de la hipótesis nula.

\section{RESULTADOS}

La tabla 2 muestra valores curtosis cercanos al cero que fueron interpretados como prerrequisitos para el análisis multivariable. Es decir, el instrumento en términos generales parece distribuirse en momentos que pueden ser correlacionados entre sí y por ello son recomendables las estimaciones de validez y confiabilidad.

La tabla 2 muestra correlaciones mayores a 0,300 e inferiores a 
Tabla 2. Descriptivos, validez y confiabilidad del instrumento.

\begin{tabular}{|c|c|c|c|c|c|c|c|c|c|c|c|c|}
\hline & Reactivo & $\mathbf{M}$ & DE & $\mathbf{A}$ & F1 & $\mathbf{F 2}$ & $\mathbf{F 3}$ & F4 & $\mathbf{F 5}$ & F6 & F7 & F8 \\
\hline R1 & $\begin{array}{l}\text { Mi superior reconoce mis } \\
\text { méritos personales }\end{array}$ & 3,05 & 0,28 & 0,721 & 0,391 & & & & & & & \\
\hline R2 & $\begin{array}{l}\text { Mi superior ignora mis } \\
\text { atributos físicos }\end{array}$ & 3,46 & 0,30 & 0,725 & 0,403 & & & & & & & \\
\hline R3 & $\begin{array}{l}\text { Mi superior ignora mis } \\
\text { colaboración }\end{array}$ & 3,08 & 0,56 & 0,749 & 0,506 & & & & & & & \\
\hline R4 & $\begin{array}{l}\text { Mi superior reconoce mi } \\
\text { capacidad }\end{array}$ & 3,04 & 0,18 & 0,793 & 0,624 & & & & & & & \\
\hline R5 & $\begin{array}{l}\text { El sexo opuesto admira mis } \\
\text { atributos físicos }\end{array}$ & 2,94 & 0,25 & 0,703 & & 0,405 & & & & & & \\
\hline R6 & $\begin{array}{l}\text { El sexo opuesto reconoce } \mathrm{mi} \\
\text { abnegación }\end{array}$ & 2,48 & 0,39 & 0,794 & & 0,571 & & & & & & \\
\hline R7 & $\begin{array}{l}\text { El sexo opuesto ignora mi } \\
\text { colaboración }\end{array}$ & 2,04 & 0,47 & 0,791 & & 0,682 & & & & & & \\
\hline R8 & $\begin{array}{l}\text { El sexo opuesto admira mi } \\
\text { aporte al equipo }\end{array}$ & 2,39 & 0,18 & 0,739 & & 0,732 & & & & & & \\
\hline R9 & $\begin{array}{l}\text { Mi superior enaltece mi } \\
\text { belleza física }\end{array}$ & 3,01 & 0,26 & 0,729 & & & 0,516 & & & & & \\
\hline R10 & $\begin{array}{l}\text { Mi superior ridiculiza mis } \\
\text { atributos físicos }\end{array}$ & 3,82 & 0,04 & 0,740 & & & 0,663 & & & & & \\
\hline R11 & $\begin{array}{l}\text { Mi superior enfatiza mi } \\
\text { inteligencia }\end{array}$ & 3,26 & 0,47 & 0,730 & & & 0,782 & & & & & \\
\hline R12 & $\begin{array}{l}\text { Mi superior acentúa mis } \\
\text { aportes }\end{array}$ & 3,57 & 0,37 & 0,751 & & & 0,305 & & & & & \\
\hline R13 & $\begin{array}{l}\text { El sexo opuesto admira mis } \\
\text { ideas }\end{array}$ & 2,83 & 0,31 & 0,792 & & & & 0,614 & & & & \\
\hline R14 & $\begin{array}{l}\text { El sexo opuesto ridiculiza mis } \\
\text { críticas }\end{array}$ & 2,79 & 0,51 & 0,749 & & & & 0,725 & & & & \\
\hline R15 & $\begin{array}{l}\text { El sexo opuesto debate mis } \\
\text { errores }\end{array}$ & 2,57 & 0,47 & 0,751 & & & & 0,365 & & & & \\
\hline R16 & $\begin{array}{l}\text { El sexo opuesto discute mi } \\
\text { belleza física }\end{array}$ & 2,93 & 0,44 & 0,757 & & & & 0,465 & & & & \\
\hline R17 & $\begin{array}{l}\text { Mi superior considera que } \\
\text { soy imprescindible }\end{array}$ & 3,05 & 0,36 & 0,758 & & & & & 0,725 & & & \\
\hline R18 & $\begin{array}{l}\text { Mi superior asume que debo } \\
\text { ser sexy }\end{array}$ & 3,17 & 0,25 & 0,726 & & & & & 0,321 & & & \\
\hline R19 & $\begin{array}{l}\text { Mi superior considera que } \\
\text { soy capaz }\end{array}$ & 3,08 & 0,18 & 0,761 & & & & & 0,425 & & & \\
\hline R20 & $\begin{array}{l}\text { Mi superior asume que soy } \\
\text { inteligente }\end{array}$ & 3,46 & 0,59 & 0,783 & & & & & 0,537 & & & \\
\hline R21 & $\begin{array}{l}\text { El sexo opuesto admira mi } \\
\text { cuerpo }\end{array}$ & 2,70 & 0,92 & 0,749 & & & & & & 0,395 & & \\
\hline R22 & $\begin{array}{l}\text { El sexo opuesto alaga mi } \\
\text { belleza física }\end{array}$ & 2,63 & 0,06 & 0,746 & & & & & & 0,461 & & \\
\hline R23 & $\begin{array}{l}\text { El sexo opuesto invade mi } \\
\text { privacidad sentimental }\end{array}$ & 2,81 & 0,21 & 0,716 & & & & & & 0,537 & & \\
\hline R24 & $\begin{array}{l}\text { El sexo opuesto está al } \\
\text { pendiente de mis relaciones } \\
\text { amorosas }\end{array}$ & 2,69 & 0,46 & 0,751 & & & & & & 0,657 & & \\
\hline R25 & $\begin{array}{l}\text { Mi superior habla mal del } \\
\text { sexo opuesto }\end{array}$ & 3,05 & 0,58 & 0,753 & & & & & & & 0,457 & \\
\hline R26 & $\begin{array}{l}\text { Mi superior considera que el } \\
\text { sexo opuesto debe quedarse } \\
\text { en casa }\end{array}$ & 3,94 & 0,48 & 0,759 & & & & & & & 0,521 & \\
\hline R27 & $\begin{array}{l}\text { Mi superior dice que el sexo } \\
\text { opuesto debe ser mantenido }\end{array}$ & 3,17 & 0,88 & 0,751 & & & & & & & 0,678 & \\
\hline R28 & $\begin{array}{l}\text { Mi superior señala que el } \\
\text { sexo opuesto debe cuidar a } \\
\text { los hijos }\end{array}$ & 3,26 & 0,61 & 0,759 & & & & & & & 0,789 & \\
\hline
\end{tabular}




\begin{tabular}{|c|c|c|c|c|c|c|c|c|c|c|c|c|}
\hline & Reactivo & $\mathbf{M}$ & DE & $\mathbf{A}$ & F1 & F2 & F3 & F4 & F5 & F6 & F7 & F8 \\
\hline R29 & $\begin{array}{l}\text { El sexo opuesto puede lograr } \\
\text { los objetivos sin mi ayuda }\end{array}$ & 2,88 & 0,38 & 0,759 & & & & & & & & 0,567 \\
\hline R30 & $\begin{array}{l}\text { El sexo opuesto requiere de } \\
\text { mi colaboración para } \\
\text { alcanzar las metas }\end{array}$ & 2,71 & 0,31 & 0,741 & & & & & & & & 0,624 \\
\hline R31 & $\begin{array}{l}\text { El sexo opuesto tendría otros } \\
\text { propósitos sin mi ayuda }\end{array}$ & 2,68 & 0,64 & 0,746 & & & & & & & & 0,736 \\
\hline R32 & $\begin{array}{l}\text { El sexo opuesto tendria los } \\
\text { mismos méritos sin mi apoyo }\end{array}$ & 2,90 & 0,48 & 0,784 & & & & & & & & 0,351 \\
\hline
\end{tabular}

Método de extracción: ejes principales, rotación promax. Adecuación y Esfericidad $\left[\mathrm{X} 2=323,45(35 \mathrm{gl}) \mathrm{p}=0,000 ; \mathrm{KMO}=0,778 \int \mathrm{M}=\right.$ Media, $\mathrm{DE}=$ desviación Estándar, $\mathrm{A}=$ Alfa de Crombach quitando el valor del ítem. $\mathrm{F} 1=\mathrm{Acoso}$ $(23 \%$ de la varianza), F2 = Benevolencia $(22 \%$ de la varianza), F3 = Cosificación $(21 \%$ de la varianza), F4 = Despersonalización $(20 \%$ de la varianza), $\mathrm{F} 5=$ Estigma $(6 \%$ de la varianza), $\mathrm{F} 6=$ Hostigamiento $(4 \%$ de la varianza), $\mathrm{F} 7=$ Prejuicio ( $3 \%$ de la varianza), F8 = Subyugación (1\% de la varianza). Todos los ítems se responden con alguna de cinco opciones: desde $0=$ no se parece mucho a mi situación hasta $4=$ se parece mucho a mi situación

\section{Fuente: Elaboración propia}

0,900 las cuales se establecieron como el umbral requerido para interpretar la validez de constructo. A pesar de que el análisis de componentes principales con rotación varimax distribuyó los pesos factoriales en ocho dimensiones, los porcentajes de varianza explicada señalan que sólo cuatro cumplen con el mínimo indispensable para el contraste de hipótesis y la aceptación del ajuste entre las relaciones especificadas y los datos obtenidos.

De este modo los factores de acoso, benevolencia, cosificación y despersonalización explican el $86 \%$ de la varianza total. En el caso del acoso se configuró con los reactivos 1 a 4 explicando el $23 \%$ de la varianza, la benevolencia incluyó los ítems 5 a 8 y explicó el $22 \%$ de la varianza, la cosificación fue establecida por los indicadores 9 a 12 y obtuvo el $21 \%$ de varianza explicada. Por último, la despersonalización fue indicada por los síntomas 13 a 16 y obtuvo el $20 \%$ de la varianza.

La tabla 3 muestra las correlaciones entre los ocho factores en las que es posible observar su nivel de significancia, pero con valores de relaciones asociativas cercanas al cero e interpretables como espurias por su correlación con otros factores no especificados. 
Tabla 3. Correlación entre factores.

\begin{tabular}{|c|c|c|c|c|c|c|c|c|}
\hline & $\mathbf{F 1}$ & $\mathbf{F 2}$ & $\mathbf{F 3}$ & $\mathbf{F 4}$ & $\mathbf{F 5}$ & $\mathbf{F 6}$ & $\mathbf{F 7}$ & $\mathbf{F 8}$ \\
\hline $\mathbf{F 1}$ & $\mathbf{1 , 0 0 0}$ & & & & & & & \\
\hline $\mathbf{F 2}$ & $0,292^{* *}$ & 1,000 & & & & & & \\
\hline $\mathbf{F 3}$ & $0,293^{* *}$ & $0,284^{*}$ & 1,000 & & & & & \\
\hline $\mathbf{F 4}$ & $0,294^{*}$ & $\mathbf{0 , 6 2 9 ^ { * * }}$ & $0,263^{*}$ & 1,000 & & & & \\
\hline $\mathbf{F 5}$ & $0,283^{* *}$ & $\mathbf{0 , 4 9 3 ^ { * * }}$ & $0,123^{*}$ & $0,125^{*}$ & 1,000 & & & \\
\hline $\mathbf{F 6}$ & $0,202^{* *}$ & $0,214^{*}$ & $0,124^{*}$ & $\mathbf{0 , 5 4 6 ^ { * * * }}$ & $0,136^{*}$ & 1,000 & & \\
\hline $\mathbf{F 7}$ & $0,181^{*}$ & $0,126^{*}$ & $\mathbf{0 , 4 5 3 ^ { * * * }}$ & $0,194^{*}$ & $0,137^{* *}$ & $0,231^{*}$ & 1,000 & \\
\hline $\mathbf{F 8}$ & $\mathbf{0 , 6 7 8 ^ { * * * }}$ & $0,115^{* *}$ & $0,263^{*}$ & $0,175^{*}$ & $0,147^{* *}$ & $0,236^{*}$ & $0,136^{*}$ & 1,000 \\
\hline
\end{tabular}

Nivel de significancia: ${ }^{*}=0,05 ;{ }^{* *}=0,01 ;{ }^{* * *}=0,001$

\section{Fuente: Elaboración propia}

El primer factor relativo al acoso labora se asoció significativamente con la subyugación $(r=0,678 ; p=$ $0,001)$. A medida que la violencia formativa se materializa como acoso también se intensifica en cuanto al confinamiento de la víctima.

No obstante, la benevolencia laboral al relacionarse con la despersonalización y con el estigma $(r=$ 0,629 y $r=0,493$ ambos con $p=$ $0,001)$ parece indicar que un aumento en los comentarios que atribuyen al sexo opuesto una función laboral en relación a un posicionamiento en la familia está vinculado con un incremento en la indiferencia de sus méritos y la asignación de atributos generales a su rol familiar, laboral o social.
Por su parte, la correlación entre la cosificación y el prejuicio $(r=$ 0,$453 ; p=0,001$ ) advierten sobre las relaciones laborales en las que los sexos son considerados instrumentos en torno al logro de objetivos que se asocian con roles de género.

Por último, la despersonalización con el hostigamiento $(r=0,546 ; p=$ $0,001)$ parece evidenciar un proceso en el que el desconocimiento de capacidades y meritos laborales estaría asociado al enaltecimiento de atributos físicos.

A partir de las correlaciones esgrimidas se especificó un modelo reflejante de la violencia formativa 
organizacional. Los ocho factores validados en los que la benevolencia es el indicador más reflejante $(\beta$ $=0,69$ ), evidencian la violencia formativa en la institución donde se llevó a cabo el estudio parece estar indicada por un discurso disuasivo de la equidad y el consenso (véase Figura 3).

Sin embargo, el parámetro de ajuste y residual $[\mathrm{X} 2=15,25(2 \mathrm{gl}) \mathrm{p}$ $=0,000 ; \mathrm{GFI}=0,950 ; \mathrm{RMR}=0,009]$ determinaron el rechazo de la hipótesis nula.
Es cierto que la benevolencia es un síntoma preponderante de la violencia formativa, pero los ocho indicadores que debieran explicitarla no corresponden con las respuestas a los ítems que miden cada una de sus dimensiones.

\section{DISCUSIÓN}

El presente estudio ha establecido como indicador preponderante de la violencia formativa a la benevolencia. A partir de esta relación reflejante se infiere que en la muestra de estudio se gesta un discurso relativo al enaltecimiento de la abne-

Figura 3. Modelo estructural.

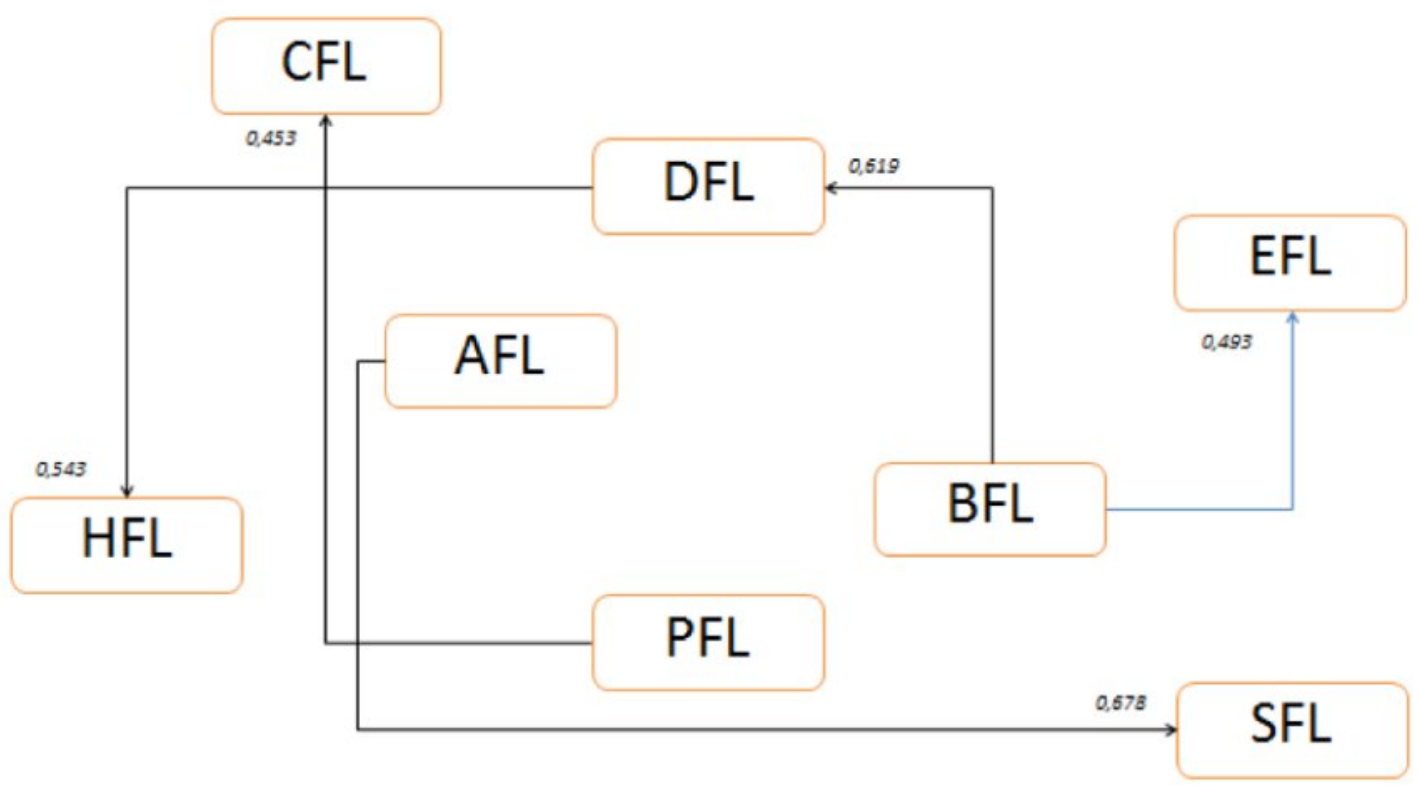

Fuente: Elaboración propia 
gación y la atención como atributos generales de las víctimas en su proceso de formación laboral.

Sin embargo, en el estudio de Carreón (2014) la violencia social fue indicada por un sexismo hostil en el que la identidad de género masculina inhibía el desarrollo de la identidad de género femenina.

Por el contrario, en el presente estudio la identidad de género parece ser una condición sobre la cual se gestan discursos benevolentes que confinan la función de la identidad femenina al cuidado y atención del grupo laboral o equipo de trabajo.

El aporte del presente estudio al estado del conocimiento estriba en que el clima organizacional al ser considerado como un factor determinante de las relaciones interpersonales y las relaciones de tareas, podría estar conformado por una violencia formativa.

Empero, es necesario explorar las dimensiones del clima organizacional ya que la violencia laboral es sólo un aspecto de las relaciones que se pueden llegar a establecer entre los empleados y directivos.

Es cierto que la benevolencia explicaría la ausencia de un sexismo hostil en las organizaciones y anticiparía el hostigamiento o el acoso laboral, pero su porcentaje de varianza explicada en el clima laboral sería menor ya que las organizaciones están enfocadas a responder a las demandas laborales más que a observar las relaciones equitativas $y$ libres de violencia entre sus talentos.

\section{CONCLUSIÓN}

La formación laboral, entendida como un proceso de asimetría entre los talentos y líderes, incluye ocho factores relativos al prejuicio, despersonalización, benevolencia, hostigamiento, subyugación, cosificación, estigma y acoso, los cuales al interactuar explican el proceso de desinstitucionalización y despersonalización que es a la vez sustituido por un ciclo de violencia y un circulo de agresión, los cuales inhiben la formación laboral que el mercado laboral requiere o espera de las instituciones académicas, aunque el tipo de estudio no expe- 
rimental y exploratorio, el tipo de selección muestral no probabilística e intencional, así como el tipo de análisis factorial exploratorio con rotación promax limitan los resultados al contexto y a la muestra de estudio.

Es menester llevar a cabo una extensión del estudio en contextos $y$ muestras diferentes con la finalidad de establecer los determinantes más predictivos de la violencia - la colaboración laboral, para ello es necesario realizar un estudio cuasi pre o cuasi experimental con una selección muestral estratificada, aleatoria y representativa de las IES en el contexto de la evaluación, acreditación y certificación de sus procesos.

\section{REFERENCIAS}

Adenike, A. (2011). Organization climate as a predictor of empleyee job satisfaction. Business Intelligence Journal. 4, 151-166

Anwar, F. y Norulkamar, U. (2012). Mediating role of organizational commitment among leaderschip and employee outcomes, and empirical evidence from telecom sector. Processing International Seminar on Industrial Engineering and Management 2, 116-161
Arnau, L. y Montané, J. (2010). Aportaciones sobre la relación conceptual entre actitud y competencia, desde la teoría del cambio de actitudes. Journal of Research in Educational Psychology. 8, 1283-1302

Berdecia, Z., González, J. y Carrasquillo, C. (2012). Estilos de liderazgo para el éxito organizacional: estudios de casos múltiples en empresas. Revista de Estudios Avanzados de Liderazgo, 1, 21-32

Borjas, L. (2010). El espíritu empresarial desde las representaciones sociales: caso Venezuela. Ciencias Sociales, 5, 149165

Cardon, M., Gregoire, D., Stevens, C. y Patel, P. (2013). Measuring entrepreneurial passion: conceptual foundations and scale validation. Journal of Business Venturing, 28, 373-396

Carreón, J. (2011). La lucha contra la delincuencia organizada en México. Barataria, 14, 59-74

Carreón, J. (2012). Emociones de inseguridad determinantes de la desconfianza a la autoridad pública. Revista Electrónica de Psicología Política, 31, 52-62

Carreón, J. (2013). Teorías de la seguridad pública y percepción del delito. Margen, 71, 1-16

Carreón, J. (2014). Una exploración al estudio de la violencia. El caso mexicano. Obets, 8 (1), 59-78

Castel, G. y Freundlich, F. (2010). Percepciones de los socios y no socios cooperativista sobre la satisfacción laboral. Revesco. 103, 33-58 
Castro, M. y Martins, M. (2010). The relationships between organizational climate and employee satisfaction in information and technology organization. Tydskriff vir Bredyfsielkunde. 36, 1-9

Caykoylu, S., Egri, C., Havlovic, S. y Bradley, C. (2011). Key organizational commitment antecedents for nurses, paramedical professionals and non-clinical staff. Journal of Health Organization and Management. 25, 7-33

Celik, M., Turunc, O. y Begenirbas, M. (2011). The role of organizational trust, Burnout and interpersonal deviance for achieving organizational performance. International Journal of Business and Management Studies. 3, 179-190

Cerrón, L. (2010). El papel del mercado en la construcción de los modelos de formación profesional: la mercantilización del sistema. Reifop, 13, 54-63

Chiang, M., Méndez, G. y Sánchez, G. (2010). Cómo influye la satisfacción laboral sobre el desempeño: caso empresa de reatail. Revista Theoria. 19, 21-36

Chinchilla, N. y Cruz, H. (2010). Diversidad y paradigmas de empresa: un nuevo enfoque. Revista Empresa y Humanismo, 14, 47-79

Coronel, A. (2010). Capacitación del capital humano para una inversión de desarrollo. Eureka, 7, 71-76

Cuesta, A. (2012). Modelo integrado de gestión humana y del conocimiento: una tecnología de aplicación. Revista Venezolana de Gerencia, 57, 86-98

Díaz, C., Hernández, R. y Roldán, J. (2012). A structural model of the antecedents to entrepreneurial capacity. International Small Business Journal, 30, 850-872
Díaz, S. (2013). Lo humano en la Teoría de las Organizaciones. Visión gerencial, $12,45-57$

Figeiredo, H., Grau, E., Gil, P. y García, J. (2012). Síndrome de quemarse por el trabajo y satisfacción laboral en profesionales de enfermería. Psocthema, 24, 271-276

Fuentes, A., Herrero, J. y Gracia, E. (2010). Internet y apoyo social: sociabilidad online y ajuste psicosocial en la sociedad de la información. Acción

Psicológica. 7, 9-15

Fuentes, F. y Sánchez, S. (2010). Análisis del perfil emprendedor: una perspectiva de género. Estudios de Economía Aplicada, 28, 1-28

Galindo, R. y Echavarría, M. (2011). Diagnóstico de la cultura emprendedora en la escuela de ingeniería de Antioquia. Revista de la Escuela de Ingeniería de Antioquia, 15, 85-94

Gargallo, A. (2010). Percepciones de los socios y no socios cooperativistas sobre la satisfacción laboral. Revesco, 103, 3358

Gil, C. (2010). Comunicadores corporativos: desafíos de una formación profesional por competencias en la era global. Cuadernos, 33, 49-59

González, F., Sánchez, S. y López, T. (2011). Satisfacción laboral como factor crítico para la calidad. Estudios y Perspectivas en Turismo, 20, 1047-1068

Guillén, M. Lleó, A. y Perles, G. (2011). Repensando la confianza como factor crítico en la gestión organizativa. Cuadernos de Gestión. 11. 33-47 
Holden, R. y Karsh, B. (2010). Technology Acceptance Model: its past and its future in health care. Jorunal of Biomedical Informatics. 43, 169-172

Long, H. (2013). The relationships among learning orientation, market orientation, entrepreneurial orientation, and firm performance. Management Review, 20, 37-46

López, L. y López, J. (2011). Los modelos de adopción de tecnologías de información desde el paradigma actitudinal. Ebape. 9, 176-196

Manning, A. (2010). Development of the psychological climate scale for small business. Journal of New Business Ideas \& Trends. 8, 50-63

Medina, C. (2010). Los estudios organizacionales: entre la unidad y la fragmentación. Cinta de Moebio, 38, 91-109

Molero, F., Recio, P., y Cuadrado, I. (2010). Liderazgo transformacional y transaccional: un análisis de la estructura factorial del multifactor Leardership Questionaire (MLQ). Psicothema. 22, 495-501

Morales, A., Ariza, A. y Muñiz, N. (2012). El emprendedor social y e-empowerment de las redes sociales. Revista de Economía Pública, Social y Cooperativa, 75 , 152-177

Omar, A. (2010). Liderazgo transformador y satisfacción laboral: el rol de la confianza en el supervisor. Liberabit. 17 , 129-137

Orantes, S. (2011). Viabilidad del Modelo de la Aceptación de la Tecnología en las empresas mexicanas. Una aproximación a las actitudes y percepciones de los usuarios de las tecnologías de la información. Revista Digital Universitaria. 12, $1-15$
Organización de las Naciones Unidas para la Educación, la Ciencia y la Cultura (2010) Education For All. Monitoring report. New York: UNESCO

Prada, R. (2013). La adaptación al cambio y el servicio: claves del liderazgo en el mejoramiento de la productividad en las organizaciones. Revista de Estudios Avanzados de Liderazgo, 1, 45-50

Ríos, M., Téllez, M. y Ferrer, J. (2010). El empoderamiento como predictor del compromiso organizacional en las pymes. Contaduría y Administración. 231, 103-125

Rodríguez, A., Retamal, R., Lizana, J. y Cornejo, F. (2011). Clima y satisfacción laboral como predictores del desempeño: en una organización estatal chilena. Salud y Sociedad. 2, 219-234

Rojas, R., García, V. y García, E. (2011). The influence on corporate entrepreneurship of technological variables. Industrial management \& Data System, 111, 984-1005

Shrrof, R., Denenn, C. y Ng, E. (2011). Analysis of the Technology Acceptance Model in examining student's behavioral intention to use an e-portfolio system. Australasian Journal of Educational Technology. 27, 600-618

Sobrados, L. y Fernández, E. (2010). Competencias emprendedoras y desarrollo del espíritu empresarial en los centros educativos. Educación XXI, 13, 15-38

Tayo, E. y Adeyemi, A. (2012). Job involvement \& organizational commitment as determinants of job performance among educational resource centre personal. European Journal of Globalization and Development Research. 5, 301-313

Teh, P, Chong, C, Yong, C. y Yew, S. (2010). Internet self-efficacy, computer 
self-efficacy, and cultural factor on knowledge sharing behavior. African Journal of Business Management. 4, 4086-4095

Vargas, J. (2011). Organización del trabajo y satisfacción laboral: un estudio de caso en la industria del calzado. Revista Electrónica Nova Scientia. 4, 172-204

Vargas, M. y Arenas, M. (2012). Competencias emprendedoras en estudiantes de psicopedagogía de la Universidad Pedagógica y Tecnológica de Colombia. Revista de Estudios Avanzados de Liderazgo, 1, 25-30

Yáñez, R., Arenas, M. y Ripoll, M.

(2010). El impacto de las relaciones interpersonales en la satisfacción laboral. Liberabit. 16, 193-202

Yuangion, Y. (2011). The impact of strong ties on entrepreneurial intention. An empirical study based on the mediating role of self-efficacy. Journal Entrepreneurship, 3, 147-158

Zampetakis, L. y Moustakis, V. (2013). Entrepreneurial behavior in the Grekk public sector. Emerald, 13, 1-7 